\title{
Homem de 46 anos com suspeita de neoplasia pulmonar e hemiparésia direita
}

\section{6 year male with suspected lung neoplasm and right hemiparesis}

Apresentamos o caso de um homem de 46 anos, fumador, com opacidade nodular do ápice do pulmão direito em radiografia torácica (RTx) (figura 1) realizada no Serviço de Urgência (SU) por quadro arrastado de dispneia e tosse. Teve alta sob antibioterapia e com reavaliação agendada em consulta externa, à qual faltou. Referenciado ao mesmo SU cerca de um ano depois, por hemiparésia direita com 12 horas de evolução; na TAC cerebral, imagem compatível com enfarte lacunar parietal esquerdo. Mantinha queixas de dispneia e tosse produtiva, agora acompanhadas de emagrecimento e dor na região escapular direita. A RTx mostrou opacidade ocupando agora todo o lobo superior do pulmão direito (figura 2). Ficou internado por acidente vascular cerebral isquémico e suspeita de neoplasia pulmonar. No primeiro dia de internamento, desenvolveu quadro de retenção urinária, paraplegia e hipostesia dos membros inferiores e da parede abdominal (nível sensitivo em T4). A ressonância magnética nuclear da coluna dorsolombar revelou extensão da lesão pulmonar ao canal raquidiano (seta) e compressão da medula espinal com sofrimento medular (cabeça de seta) (figura 3). Iniciou corticoterapia e foi submetido a radioterapia urgente, com recuperação parcial da sensibilidade táctil, mas sem reversão da retenção urinária ou da paraplegia. A biópsia da massa revelou um carcinoma pulmonar de pequenas células. Iniciou quimioterapia com o esquema CPVP - cisplatina, carboplatina e etoposídeo. Faleceu ao $22^{\circ}$ dia de internamento, na sequência de intercorrência infecciosa nosocomial.

0 síndrome de compressão medular é uma complicação neoplásica frequente, sendo em cerca de $20 \%$ dos casos a sua primeira manifestação. ${ }^{1}$ Pode causar dor e lesão neurológica potencialmente irreversível. A localização torácica é a mais frequente (cerca de $60 \%$ dos casos) $)^{2}$. 0 principal factor prognóstico relaciona-se com 0 estado neurológico pré-tratamento, pelo que o diagnóstico precoce é fundamental ${ }^{3}$.

\section{Bibliografía}

1. Schiff D, O'Neill BP, Suman VJ. Spinal epidural metastasis as the initial manifestation of malignancy: clinical features and diagnostic approach. Neurology 1997;49:452.

2. Cole JS, Patchell RA. Metastatic epidural spinal cord compression. Lancet Neurol. 2008;7(5):459.

3. Holt T, Hoskin P, Maranzo E, Sahgal A, Schild SE, Ryu S, Loblaw A. Malignant epidural spinal cord compression: the role of external beam radiotherapy. Curr Opin Support Palliat Care 2012 Mar;6(1):103-8.

Diagnóstico

\section{Síndrome de compressão medular por massa pulmonar}

Ana L Silva. Susana Reis.

Serviço de Medicina Interna. Centro Hospitalar de São João. Porto. Portugal

Correspondencia: alrosilva@gmail.com

Como citar este artículo: Silva AL, Susana Reis $S$.

Homem de 46 anos com suspeita de neoplasia pulmonar e hemiparésia direita. Galicia Clin 2016; 77 (4): 193 Recibido: 04/05/16 ; Aceptado: 26/06/16
Figura 1. Opacidade nodular do ápice do pulmão direito em radiografia torácica

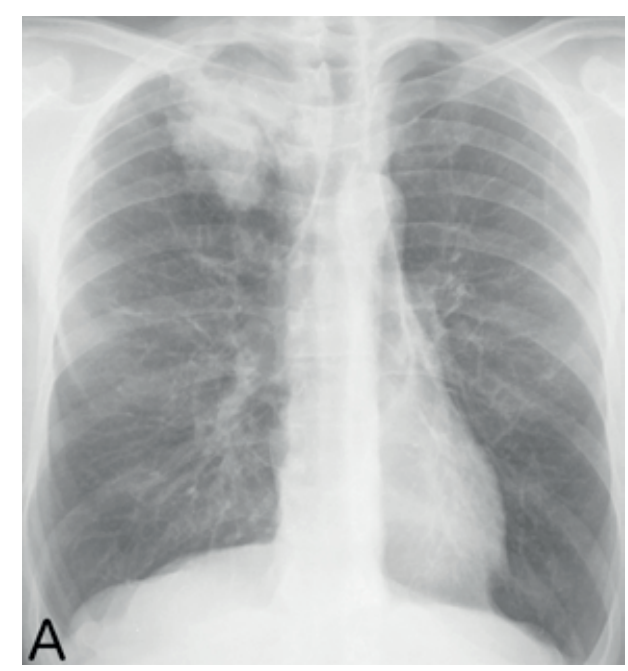

Figura 2. Radiografia torácica 1 ano depois, com opacidade ocupando agora todo o lobo superior do pulmão direito.

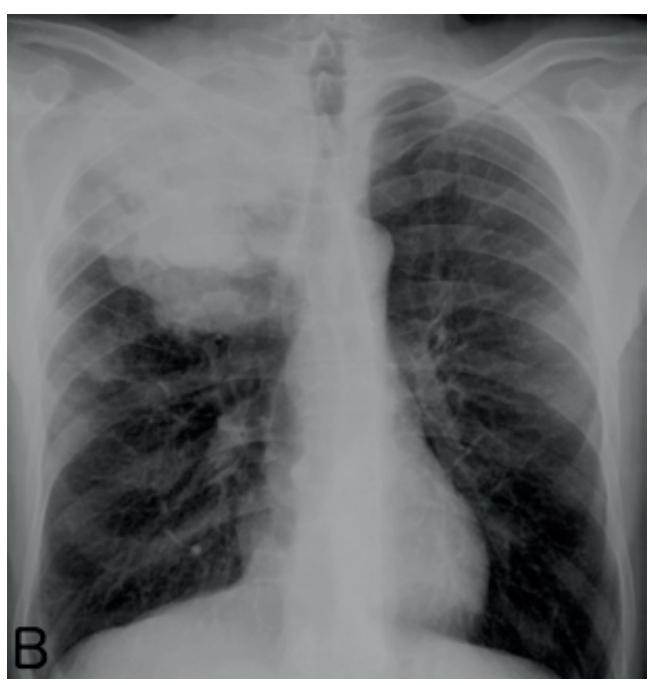

Figura 3. RMN da coluna dorsolombar: extensão da lesão pulmonar ao canal raquidiano

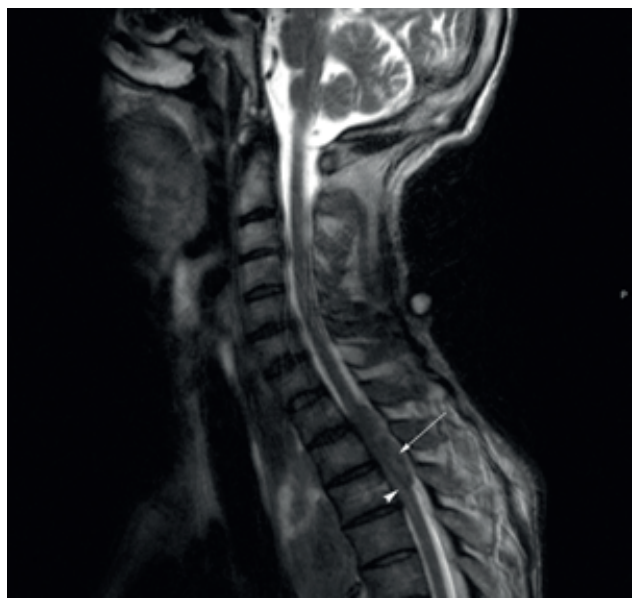

